\title{
Unexplored relationship of sleep disturbances linked to suicidal ideation and behavior in postural orthostatic tachycardia syndrome
}

This article was published in the following Dove Press journal:

Nature and Science of Sleep

24 July 2017

Number of times this article has been viewed

\author{
Muhammad Nabeel Shafqat ${ }^{\prime}$ \\ Muhammad Aadil ${ }^{2}$ \\ Maria Shoaib ${ }^{3}$ \\ 'Department of Medicine, University \\ of Medical Sciences "Serafin Ruiz \\ de Zarate" Villa Clara (UCMVC), \\ Villa Clara, Cuba; ${ }^{2}$ Department of \\ Psychiatry, Rush University Medical \\ Center, Chicago, IL, USA; ${ }^{3}$ Department \\ of Medicine, Dow Medical College, \\ Dow University of Health Sciences, \\ Karachi, Pakistan
}

\section{Dear editor}

We read with great interest the currently published article written by Pederson and Brook ${ }^{1}$ entitled "Sleep disturbance linked to suicidal ideation in postural orthostatic tachycardia syndrome". Awareness of postural orthostatic tachycardia syndrome (POTS) has increased in recent years. However, sleep disturbance has not been thoroughly investigated as a cause of increased suicidal risk in patients with POTS. We would like to applaud the authors on conducting this novel cross-sectional study to understand and highlight the potential relationship between sleep disturbances and increased risk of suicide in patients suffering from POTS. ${ }^{1}$

POTS is one of the several autonomic nervous system disorders, and it is characterized by an increase in the heart rate that occurs upon standing (adults $>130$ beats per minute and adolescents $>140$ beats per minute). ${ }^{2}$ The pathophysiology of POTS is heterogeneous. It includes impairment of sympathetic nervous system-mediated vasoconstriction, exaggerated sympathetic drive, dysregulation of intravascular volume and deconditioning. ${ }^{3}$ It is characterized by a variety of associated symptoms such as palpitations and facial flushing. Increased circulating catecholamine levels and hyperadrenergism are possible underlying pathophysiological mechanisms. ${ }^{4}$ Orthostatic and non-orthostatic symptoms coexist. Orthostatic symptoms include dizziness, diffuse weakness, equilibrium problems and instability; non-orthostatic symptoms include dryness in eyes and mouth and gastrointestinal problems include nausea, vomiting, abdominal pain, early satiety and diarrhea alternating with constipation. ${ }^{4}$ Many patients present with sleep disturbances, including poor night time sleep, ${ }^{4,5}$ sleep fragmentation, reduced percentage of rapid eye movement sleep and daytime sleepiness. ${ }^{5}$ These disturbances might be caused by the activation of the sympathetic nervous system or due to chronic pain and a hyperaroused state. ${ }^{5}$

We would like to mention certain limitations of this study that may be important to consider before generalizing results. On the one hand, not all studies have found gross sleep disturbances in patients diagnosed with POTS. For example, a prospective clinical trial conducted from June 2010 to September 2011 found no significant differences in polysomnographically recorded sleep efficiency or arousal patterns in patients with POTS as compared to a control group. ${ }^{5}$ Depression may be one of the causes of increased suicidal ideation in these patients as its presence or absence was not evaluated. ${ }^{1}$ Although a meta-analysis revealed that sleep disturbance is related to an increased relative risk of suicidal ideation and suicidal attempt, ${ }^{6}$ the relative risk of suicide
Shafqat

Department of Medicine, University of Medical Sciences "Serafin Ruiz de Zarate" Villa Clara (UCMVC), Carretera a Acueducto y Circunvalacion. Postal Code 51200 , Villa Clara, Cuba

Tel +535334 I433

Email anm55II@gmail.com 
ranged from 1.95 to 2.95 in unadjusted studies. Associations were comparatively smaller, but still were significantly high among adjusted studies. It can be deduced from this study that depression is not the sole cause of the relation between sleep disturbances and suicide variables. ${ }^{6}$ However, most of the other recent studies have shown that sleep disturbances associated with an increased suicidal ideation may be due to a related cofactor of increased depression. ${ }^{6}$ Therefore, depression must be taken into consideration while assessing studies linking sleep disturbances to suicidal behavior and ideation.

On the other hand, patients were interviewed online about their sleep patterns. Online surveys have many scientific and methodological limitations, most important to mention is selection bias on behalf of people who decide to take the survey - as opposed to a scientifically selected sample that is more representative of the general population. ${ }^{7}$ This bias also includes bias due to Internet access, nonresponse bias, recall bias and stakeholder bias. Finally, there can be difficulties verifying the participants. Thus, online surveys can be unreliable. ${ }^{7}$

We contend that one of the most important steps to improve knowledge about risk factors for POTS is to precisely characterize the source population as the study base. ${ }^{8} \mathrm{We}$ encourage further studies to explore any association between sleep disturbances linked to suicidal ideation and POTS.

\section{Disclosure}

The authors report no conflicts of interest in this communication.

\section{References}

1. Pederson CL, Brook BJ. Sleep disturbance linked to suicidal ideation in postural orthostatic tachycardia syndrome. Nat Sci Sleep. 2017;9:109-115.

2. Thieben MJ, Sandroni P, Sletten DM, et al. Postural orthostatic tachycardia syndrome: the mayo clinic experience. Mayo Clin Proc. 2007;82(3): 308-313.

3. Benarroch EE. Postural tachycardia syndrome: a heterogeneous and multifactorial disorder. Mayo Clin Proc. 2012;87(12):1214-1225.

4. Deb A, Morgenshtern K, Culbertson CJ, Wang LB, Hohler AD. A survey-based analysis of symptoms in patients with postural orthostatic tachycardia syndrome. Proc (Bayl Univ Med Cent). 2015;28(2):157-159.

5. Mallien J, Isenmann S, Mrazek A, Haensch C. Sleep disturbances and autonomic dysfunction in patients with postural orthostatic tachycardia syndrome. Front Neurol. 2014;5:118.

6. Pigeon WR, Pinquart MF, Conner K. Meta-analysis of sleep disturbance and suicidal thoughts and behaviors. J Clin Psychiatry. 2012;73(9):e1160-e1167.

7. Duda MD, Nobile JL. The fallacy of online surveys: no data are better than bad data. Hum Dimens Wildlife. 2010;15(1):55-64.

8. Checkoway H, Pearce N, Kriebel D. Selecting appropriate study designs to address specific research questions in occupational epidemiology. Occup Environ Med. 2007;64(9):633-638.

Dove Medical Press encourages responsible, free and frank academic debate. The content of the International Medical Case Reports Journal 'Editorial' section does not necessarily represent the views of Dove Medical Press, its officers, agents, employees, related entities or the International Medical Case Reports Journal editors. While all reasonable steps have been taken to confirm the content of each Editorial, Dove Medical Press accepts no liability in respect of the content of any Editorial, nor is it responsible for the content and accuracy of any Editorial.

\section{Publish your work in this journal}

Nature and Science of Sleep is an international, peer-reviewed, open access journal covering all aspects of sleep science and sleep medicine, including the neurophysiology and functions of sleep, the genetics of sleep, sleep and society, biological rhythms, dreaming, sleep disorders and therapy, and strategies to optimize healthy sleep. The manuscript

\section{Dovepress}

management system is completely online and includes a very quick and fair peer-review system, which is all easy to use. Visit http://www dovepress.com/testimonials.php to read real quotes from published authors. 